Check for updates

CSL Diabetes, University Hospitals of Birmingham, Birmingham, UK

2 Royal Free London NHS Foundation Trust, London, UK

3 University Hospitals Coventry and Warwickshire NHS Trust, Warwick,

4 Diabetes Research Centre and Centre for Black Minority Health, University of Leicester, Leicester, UK

Correspondence to: W Hanif wasim.hanif@uhb.nhs.uk

Cite this as: BMJ 2020;371:m4845 http://dx.doi.org/10.1136/bmj.m4845 Published: 18 December 2020

\title{
Cultural competence in covid-19 vaccine rollout
}

\author{
Vulnerable communities must not be left behind again \\ Wasim Hanif, ${ }^{1}$ Sarah N Ali, ${ }^{2}$ Kiran Patel, ${ }^{3}$ Kamlesh Khunti ${ }^{4}$
}

The development of a vaccine for SARS-CoV2 in a record nine months from concept to regulatory approval in the UK is one of the greatest scientific successes in recent history. ${ }^{1}$ However, the speed of development and approval has led some potential recipients to have concerns about the vaccine's safety. These concerns may jeopardise the vaccination programme since the effectiveness of any vaccine depends on the number of people willing to be vaccinated.

Globally, ethnic minority communities have been disproportionately affected by covid-19. Ethnicity is a major risk factor for adverse outcomes, along with age, male sex, obesity, deprivation, and comorbidities. ${ }^{2}$ Now, at the start of the UK's national vaccination programme, culturally competent conversations with ethnic minority communities are more important than ever to enable informed consent, allay genuine concerns, break down barriers to uptake, and engage facilitators for the roll-out.

One large global study reported lower levels of confidence in vaccination in several South Asian and other developing countries compared with in Europe. ${ }^{3}$ A US survey found SARS-CoV-2 vaccine hesitancy was associated with young age, lower educational attainment, and black ethnicity, ${ }^{4}$ and a UK poll suggests greater reluctance among ethnic minority and lower income groups. ${ }^{5}$ Despite reports detailing the disproportionate effect of covid-19 on ethnic minority communities in the UK, no clear recommendations were made or implemented to address concerns. ${ }^{6}$ Inadequate ethnic coding in medical records is an ongoing problem, making it difficult to identify the scale of health inequalities. Ethnic coding was introduced in $1995,{ }^{7}$ but the persistent failure of the NHS to make coding mandatory suggests that any drive to systematically tackle this issue is challenged at the outset. Furthermore, the participation of ethnic minorities in trials evaluating vaccines has been dismally low; the published data from Pfizer-BioNTech's vaccine trials reports around 4\% Asian and 9\% black participation. $^{8}$

\section{Overcoming barriers}

Cultural competence is defined as the ability of health systems to provide care to patients with diverse values, beliefs, and behaviours by tailoring delivery to meet patients' social, cultural, and linguistic needs. ${ }^{9}$ Open and mature conversations with communities are important to reassure people about the safety and efficacy of covid-19 vaccines, along with clear and accessible explanations of the accelerated authorisation process used by the UK's Medicines and Healthcare Products Regulatory Agency (MHRA).
We recently recommended that ethnic minority communities should be considered a priority for vaccination, but this is not yet in place. ${ }^{10}$ One potential alternative strategy is to use validated risk scores such as QCOVID ${ }^{11}$ that consider a range of risk factors, including comorbidities, ethnicity, age, and deprivation.

Providing local facilities for vaccination will be vital to ensure ease of access. Uptake will be reduced if people are required to travel long distances on public transport while the virus is still circulating. Vaccines should be available as close as possible to vulnerable populations, including care homes residents, older people living at home, and high risk ethnic minority communities. ${ }^{12}$ Ethnic minority adults are disproportionately represented among low paid, frontline workers, many of whom works shifts, so vaccination should be available at times most appropriate to their working patterns. ${ }^{13}$

Information about the vaccines should be widely distributed in multiple languages in both written and graphic formats to enable people from all ethnic backgrounds to make fully informed choices. No community or individual should be stigmatised for initial low uptake, as occurred earlier in the pandemic in Leicester and other areas with large ethnic minority populations. $^{2}$

The Joint Committee on Vaccination and Immunisation and Public Health England should launch information campaigns led by community leaders, faith leaders, local healthcare providers and practitioners, in conjunction with trusted third sector alliances such as Community Champions, to increase positive messaging around vaccination and counteract disinformation. Data suggest the Indian subcontinent has some of the highest users of social media based messaging services, ${ }^{14}$ with many relying on this unregulated medium for accessing news, including medical advice. Digital platforms and innovative campaigns should be initiated to counter misinformation on these platforms. Anyone with legitimate concerns about vaccination should not be dismissed as an "anti-vaxxer" but heard and responded to respectfully.

Positive, evidence based, and appropriately targeted messaging about vaccination should stress the personal, economic, and social benefits of vaccination, including the ability to celebrate festivals, marriages, and other social events safely, and to protect vulnerable adults in multigenerational families. Such messaging should be coupled with clear information about the higher risk of severe illness and death from covid-19 among ethnic minority communities globally. 
As an early adopter of mass vaccination, the UK's NHS has a unique opportunity to show the international community a vaccination programme rooted in equality, diversity, and cultural competence that meets the needs of everyone. We must seize this opportunity with both hands.

Competing interests: We have read and understood BMJ policy on declaration of interests and have no interests to declare.

Provenance and peer review: Not commissioned; not externally peer reviewed.

We thank the trustees of the South Asian Health Foundation for their contribution: Amitava Banerjee, Paramjit Gill, Amal Lad, Vinod Patel, Kiran Sehmi, and Harpreet Sood.

1 Mahase E. Covid-19: UK approves Pfizer and BioNTech vaccine with rollout due to start next week. BMJ2020;371:m4714. doi: 10.1136/bmj.m4714 pmid: 33268330

2 Khunti K, Routen AC, Patel K, etal. Actions to protect ethnic minority populations from covid-19 post-lockdown. BrJ Gen Pract [forthcoming].

3 de Figueiredo A, Simas C, Karafillakis E, Paterson P, Larson HJ. Mapping global trends in vaccine confidence and investigating barriers to vaccine uptake: a large-scale retrospective temporal modelling study. Lancet 2020;396:898-908. doi: 10.1016/S0140-6736(20)31558-0 pmid: 32919524

4 Fisher KA, Bloomstone SJ, Walder J, Crawford S, Fouayzi H, Mazor KM. Attitudes toward a potential SARS-CoV-2 vaccine: a survey of US adults. Ann Intern Med 2020;173:964-73. doi: 10.7326/M20-3569. pmid: 32886525

5 Royal Society for Public Health. New poll finds BAME groups less likely to want covid vaccine. 16 Dec 2020. https://www.rsph.org.uk/about-us/news/new-poll-finds-bame-groups-less-likelyto-want-covid-vaccine.html

6 Public Health England. Beyond the data: understanding the impact of COVID-19 on BAME groups. 2020. https:/assets.publishing.service.gov.uk/government/uploads/system/uploads/attachment_data/file/892376/COVID_stakeholder_engagement_synthesis_beyond_the_data.pdf

7 Gill PS, Johnson M. Ethnic monitoring and equity. BMJ1995;310:890. doi: 10.1136/bmj.310.6984.890 pmid: 7719171

8 Polack FP, Thomas SJ, Kitchin N, etalC4591001 Clinical Trial Group. Safety and efficacy of the BNT162b2 mRNA covid-19 vaccine. N Engl J Med 2020. doi: 10.1056/NEJMoa2034577 pmid: 33301246

9 Betancourt JR, Green AR, Carrillo JE. Cultural competence in health care: Emerging frameworks and practical approaches. Commonwealth Fund, Quality of Care for Underserved Populations, 2002.

10 Hassan-Smith Z, Hanif W, Khunti K. Who should be prioritised for COVID-19 vaccines? Lancet 2020;396:1732-3. doi: 10.1016/S0140-6736(20)32224-8 pmid: 33125934

11 Clift AK, Coupland CAC, Keogh RH, etal. Living risk prediction algorithm (QCOVID) for risk of hospital admission and mortality from coronavirus 19 in adults: national derivation and validation cohort study. BM/2020;371:m3731. doi: 10.1136/bmj.m3731 pmid: 33082154

12 Szczepura A. Access to health care for ethnic minority populations. Postgrad Med/2005;81:141-7. doi: 10.1136/pgmj.2004.026237 pmid: 15749788

13 Khunti K, Platt L, Routen A, Abbasi K. Covid-19 and ethnic minorities: an urgent agenda for overdue action. BMJ2020;369:m2503. doi: 10.1136/bmj.m2503 pmid: 32576558

14 WhatsApp, WeChat and Facebook Messenger apps - global usage of messaging apps, penetration and statistics. 30 Oct 2020. https://www.messengerpeople.com/global-messenger-usagestatistics/

This article is made freely available for use in accordance with BMJ's website terms and conditions for the duration of the covid-19 pandemic or until otherwise determined by BMJ. You may use, download and print the article for any lawful, non-commercial purpose (including text and data mining) provided that all copyright notices and trade marks are retained. 